\title{
EL NUDO/NODO EN LA NARRATIVA DE JULIO CORTÁZAR Y LOS CAMINOS HACIA LA HIPERFICCIÓN
}

\author{
Álvaro Llosa SANZ \\ University of California, Davis \\ Universidad de Szeged
}

\begin{abstract}
The word nudo (knot), which comes from the latin nodus, is explained in seventeen different ways in the Dictionary published by the Spanish Royal Academy. However, every definition converges in a key point: the knot as a juncture or convergence of diverse elements. In this paper, I apply these definitions to the analysis of knot and nodal methaporic structures used in Julio Cortázar's narrative: the knot starts as a literary metaphor in his early work. titled Divertimento (1949), it evolves into a nodal structure in Rayuela (1963), and finally it reachs a maximum complexity of knots and nodes in 62, modelo para armar (1968).
\end{abstract}

"tendí la mano y toqué el ovillo París, su materia infinita arrollándose a sí misma, el magma del aire y de lo que se dibujaba en la ventana, nubes y buhardillas; entonces no había desorden, entonces el mundo seguía siendo algo petrificado y establecido, un juego de elementos girando en sus goznes, una madeja de calles y árboles y nombres y meses"

(Julio Cortázar, Rayuela, cap. 2)

\section{El nudo}

La parte segunda de Divertimento, novela fechada en 1949 aunque revisada posteriormente por el autor y publicada póstumamente, ${ }^{1}$ comienza con una descripción de cómo Laura y Moña están desenredando un ovillo hasta hallarse ante la dificultad de un nudo, que impide continuar el proceso:

Perfectamente sacás el hilo y te parece que después de todo el otro ovillo no estaba tan enredado, empezás a pensar que estás perdiendo el tiempo, siempre el hilo viniendo mansito a ponerse sobre sí mismo en el cartón, lo

${ }^{1}$ David LAGMANOVICH, "Claves de Julio Cortázar en Divertimento (1949) y El examen (1950)”, in: Dispositio 44, 1993, 175. 
de más abajo tapado por lo de más arriba que en seguida es lo de más abajo (...). Todo va así perfectamente, y a vos te parece que estás perdiendo el tiempo porque el ovillo no estaba enredado, el hilo viene y viene sin tropiezo, parece increíble que de esa masa glutinosa nazca el hilillo claro que sube por el aire hasta tu mano. Y entonces oís (los dedos sienten sonar esta ruptura terrible) que algo se resiste, se pone de pronto tenso el hilo zumba envuelto en su polvillo de talco y pelusa, un nudo cierra la salida, cierra el ritmo feliz, el ovillo estaba enredado $(. . .)^{2}$

Nos topamos así, literalmente, con la primera definición de nudo: "lazo que se estrecha y cierra de modo que con dificultad se pueda soltar por sí solo, y que cuanto más se tira de cualquiera de los dos cabos, más se aprieta". Ante la apariencia de que un ovillo es sólo hilo sobre hilo, nos encontramos ante la circunstancia del nudo, que nos plantea un problema en nuestro quehacer de tirar y tirar del hilo, y nos detiene para reflexionar desde otra perspectiva las posibilidades ontológicas del ovillo mismo:

Ahí dentro entonces hay cosas que no son el hilo solamente, el ovillo no es un hilo arrollado sobre sí, dentro del mundo del ovillo entrevé ahora tu sorpresa cosas que no son hilo, ahora ya sabes que hilo más hilo no basta para dar ovillo. Un nudo, qué es un nudo, hilo mordiéndose, sí pero nudo, no solamente hilo dentro del hilo. Nudo otra cosa que hilo. Globo terrestre ovillo, ahora ves mares, continentes, una flora ahí dentro, y no te vale tirar porque resiste, tires de los paralelos, tires de los meridianos. ${ }^{4}$

El ovillo es como el mundo, y dentro de él están sus mares y continentes: sólo ahora descubrimos que hay algo más que hilo sumado, y ese algo más, esa vida oculta del ovillo, provoca el nudo y otros nudos sucesivos. Un mundo hecho de nudos: nudos son las uniones de las cordilleras, de los huesos en los animales, de las ramificaciones en árboles y plantas, las divisiones de la corredera marítima, que permite medir la velocidad de un barco por el espacio recorrido. ${ }^{5}$ El ovillo, "universo translúcido en la mano", 6 como microcosmos cuyos nudos conforman la articulación de ese universo y vincula las partes de sus elementos. Pero es este un cosmos inestable o variable, en el que la disposición de espacios y sus dimensiones son elásticas, a excepción de sus nudos:

2 Julio CORTÁZAR, Divertimento, Madrid, Alfaguara, 1988, 44-45.

${ }_{3}$ Diccionario de la Real Academia Española (DRAE), asequible en: http://www.rae.es, fecha de consulta: 3 de octubre de 2010. Voz nudo, 1.

${ }^{4}$ CORTÁZAR, op. cit., 45-46.

${ }^{5}$ DRAE, op. cit., voz nudo, 2, 3, 5, 7 y 14.

${ }^{6}$ CORTÁZAR, op. cit., 46. 
Lo sacudió todavía un rato, esperando apenas que pasara algo. Cada vez que lo muevo la entera estructura se modifica por completo, ríos y mares filamentosos cambian de tamaño y lugar, se abren lampos y se esperan relieves, pero los nudos siempre ahí como uñas rotas donde todo se agarra. ${ }^{7}$

Nudo entonces como lazo o vínculo permanente, intersección, que ahora produce el problema práctico de desanudar para poder seguir tirando del hilo; nudo en este caso gordiano, expresión por cierto que define tanto "un nudo muy enredado o imposible de desatar" como "una dificultad insoluble". 8

Tirás furiosa, porque esta cosa nueva es rebelde y te resiste, ves salir un poco del hilo, apenas un poco y adentro como un anzuelo de hilo que lo retiene, una pesca al revés y cómo estás de rabiosa. Sin salida salvo Alejandro Magno, sistema tonto añejo inútil. (46)

$Y$ este es el núcleo narrativo que presenta Divertimento: Renato pinta un cuadro que no sabe cómo desarrollar y concluir. Sus amigos, intelectuales y poetas que forman el grupo Vive como Puedas, quedan enlazados a la resolución de esa pintura incluso de forma vital, personalmente. Hay una sospechada relación entre los personajes sin rostro del cuadro y algunos de los amigos implicados, pero el enigma interrumpe la evolución de la obra. Así, el ovillo se convierte en un objeto-símbolo de la búsqueda artística, ${ }^{9}$ ovillo del mundo del artista que encuentra un nudo-problema gordiano en el desarrollo de su obra. Por una parte, este símbolo del ovillo con su nudo, que en la novela aparece primero en manos de Laura - personaje que será una de las piezas clave de ese nudo- se aviene perfectamente con la definición de nudo como "principal dificultad o duda en algunas materias", ${ }^{10}$ en este caso representada por la imposibilidad de la conclusión de un cuadro. Al mismo tiempo, este nudo tiene su reflejo e implicación -hilo sobre hilo, arrollado sobre sí, ovillo de la vida- en el conflicto-nudo que viven todos los personajes a partir del misterio del cuadro, amenazados por una resistencia inesperada que repentinamente encuentran en sus relaciones personales y los aboca a una situación cada vez más insostenible e indefinible. Cuando el narrador, Insecto, tras sus investigaciones con Marta sobre el origen real de la casa imaginada para el cuadro por Renato, decide afrontar el problema y visitar al mago Narciso, propietario de la casa imaginada y culpable de ciertas revelaciones hechas por el fantasma llamado Eufemia, le pregunta: “¿Qué razón hay para tener alucinados a

${ }^{7}$ Ibidem, 46-47.

${ }^{8}$ DRAE, op. cit., voz nudo gordiano, 3 y 4.

${ }^{9}$ LAGMANOVICH, op. cit., 179.

${ }^{10}$ DRAE, op. cit., voz nudo, 10. 
los Vigil, y neurasténico a Renato?”, 11 Insecto está buscando una respuesta a una duda insoluble y desenredar el conflicto, el nudo gordiano en que todos están envueltos y del que deben salir por el bien de su salud. Y mientras que el fantasma Eufemia trata de desanudar trabajosamente un ovillo lleno de nudos en casa del mago Narciso, ${ }^{12}$ Insecto parece decidir que nudo tal sólo se soluciona de la misma manera que Laura concluye, cien páginas atrás, el problema de su nudo: "Nada que hacer, meterle tijera y se acabó", ${ }^{13}$ y en cierto modo análogamente a Alejandro Magno y el histórico nudo, Insecto vapulea a Narciso y su fantasma, ${ }^{14}$ causantes del sortilegio sobre Renato y su grupo, y encantamiento y nudo deshecho.

Me bastó parpadear fuertemente para reducir todo a los grandes pliegues del sofá; pero quedaba el ovillo, caído sobre la alfombra y desenrollándose livianamente hasta el centro del salón, el extremo del hilo estaba aún sobre el sofá, y se prolongaba con pequeñas curvas hasta el ovillo inmóvil. Narciso había dicho que era un ovillo que Eufemia luchaba constantemente por desanudar; lo que yo vi era un hilo sin nudo alguno, de pronto un ovillo perfecto y sin nudos. ${ }^{15}$

Parece claro que el ovillo es en Divertimento, a través del conflicto del nudo, "una representación de la lucha contra lo que oprime e impide el desarrollo del ser", ${ }^{16}$ tema que marcará la narrativa de Cortázar. Al mismo tiempo, desde un punto de vista estructural, el ovillo anudado refleja perfectamente la trama narrativa del conflicto paralelo y dependiente del cuadro con los personajes, como hemos visto, y responde de manera muy visible a esa definición de nudo en materia literaria cuando se refiere "en diversos géneros literarios, [al] enlace o trabazón de los sucesos que preceden al desenlace", ${ }^{17}$ en este caso expresado en la novela a partir de una imagen literal. El cuadro es finalmente terminado, desvelando y explicitando un cambio en la relación y (des)emparejamiento de algunos protagonistas, pero aunque estas piezas hayan variado -al fin y al cabo, como dice Insecto, "lo único que se toleran son los cambios" ${ }^{18}$ el grupo sigue unido tras la crisis. En cierta manera, como el microcosmos del ovillo, se ha modificado la estructura, pero los nudos siempre ahí.

${ }^{11}$ CORTÁZAR, op. cit., 119.

${ }^{12}$ Ibidem, 120.

13 Ibidem, 46.

${ }^{14}$ Ibidem, 121-123.

${ }^{15}$ Ibidem, 124.

${ }^{16}$ LAGMANOVICH, op. cit., 188.

${ }^{17}$ DRAE, op. cit., voz nudo, 9.

${ }^{18}$ CORTÁZAR, op. cit., 134. 


\section{El nudo-nodo}

El ovillo cae al fin desenrollado sobre la alfombra de Narciso, al igual que Gregorovius mismo, personaje de Rayuela, cuando en su niñez, tirado sobre una alfombra-tapiz, viajaba con una pelota jugando a atravesar los espacios de sucesos históricos recreados en ella. ${ }^{19}$ Una forma tejida de la rayuela que es la alfombra, que es París, que es la novela en sí misma de Julio Cortázar. Rayuela, publicada en 1963, presenta en su estructura un tablero de dirección para indicar al lector dos posibles lecturas entre otras muchas: una como lectura corrida desde el capítulo 1 al 56, donde terminaría, prescindiendo de los capítulos siguientes; la otra como lectura que se inicia en el capítulo 73 y luego sigue el orden capitular marcado al final de cada uno de los capítulos. Cortázar añade ese tablero de dirección que, como un mensaje cifrado, indica cual hilo este orden aparentemente aleatorio. El lector debe elegir una de las dos guías. La primera recuerda el modo habitual de lectura de un libro; la segunda amplía la lectura-experiencia con nuevos capítulos y convierte el libro y su lectura en una rayuela literalmente, lo que la hace una auténtica novela-salto. ${ }^{20}$ Saltos que, a pesar de permitir esa segunda articulación de las partes del texto o capítulos, no son completamente aleatorios, desde el momento en que están trazados por el autor y no pemiten perderse al lector. ${ }^{21}$ Así, desde este punto de vista estructural, la importancia de organizar el texto según la matemática propuesta en la tabla de dirección es esencial, ya que da un sentido al texto previsto por el autor, lo que una lectura tradicional desde el principio hasta el final del volumen -capítulo 155- provocaría una sensación fragmentaria superior a esa lectura guiada por los saltos. ${ }^{22}$ Quizás no encontramos un énfasis $\tan$ fuerte en la aleatoriedad posible como en la sugerencia de construir la trama mediante un orden que aparenta fragmentación y azar, pero que, no obstante, busca orden y unidad. Las dos posibles lecturas permiten al lector contrastar cada una de las experiencias lectoras, colocando así al lector como experimentador en la creación y teorización literarias.

Barthes creaba en 1970 el término lexia para expresar las unidades de significación que articulan un texto, y proponía la idea de texto abierto en el que las lexias están unidas por determinados elementos significativos asociados. ${ }^{23}$

${ }^{19}$ Julio CORTÁZAR, Rayuela. Madrid, Cátedra, 1997, 280-281.

20 Italo TEDESCO, "Rayuela, novela-salto. Teoría y práctica del juego", Letras 32-33, 1976, 143-157.

21 Cfr. Maarten STEENMEIJER, "Rayuela de Julio Cortázar: novela (post)modernista", Neophilologus 79, 1995, 256-257.

22 Cfr. Jesús CAMARERO, "L'Approche matematique de l'ecriture litteraire", Nouveau Roman 4. 2, 1997, 38 .

${ }^{23}$ Roland BARTHES, S/Z, New York, Hill and Wang, 1974. 
Vannevar Bush, ya en 1945, había propuesto un sistema mecánico -llamado Memex- que enlazaría unos documentos con otros de manera asociativa, tal como funciona nuestra mente, lo que permitiría una organización de grandes cantidades de información más efectiva para las búsquedas. ${ }^{24}$ Estas ideas, surgidas casi rizomáticamente en diversos terrenos científicos e intelectuales, produjeron el nacimiento del hipertexto como realidad, ya ideado tecnológicamente durante los sesenta por Ted Nelson, y expandida como tecnología generalizada en la World Wide Web en los noventa. El teórico literario George Landow, en 1992, aludía al hipertexto como la encarnación del texto barthesiano, y lo definía así:

Text composed of blocks of words (or images) linked electronically by multiple paths, chains, or trails in an open-ended, perpetually unfinished textuality described by the terms link, node, network, web, and path. ${ }^{25}$

Precisamente en los años en que Barthes trazaba su teoría de las lexias, Julio Cortázar publicaba un libro singularísimo titulado La vuelta al día en ochenta mundos (1967), ${ }^{26}$ un conjunto de textos críticos y humorísticos muy lúdicos y personales auspiciados bajo el signo común de su admirado tocayo Julio Verne y donde trata una miscelánea de libros, autores, ideas, citas, músicas e imágenes, todo Julio en un libro. En el episodio titulado "De otra máquina célibe" (79-88), sobre una semi-ficción personal, explica Cortázar -humorísticamente seriocómo el Instituto de Altos Estudios Patafísicos de Buenos Aires le ha enviado los planos prototípicos de cierta máquina denominada Rayuel-O-Matic, diseñada específicamente para la lectura de su novela. Acompañan al texto varios esquemas de la máquina, que aparece a modo de armarito con tantas gavetas como capítulos necesarios y algunos botones que permiten regular la lectura según lo deseado y previsto por el libro en su tabla de direcciones, permitiendo incluso la lectura aleatoria al lector. Por supuesto, el equipo viene incluido con una linda camita en la que leer cómodamente junto a las gavetas que dispensarán el capítulo correspondiente. Aunque en ningún libro sobre hipertexto he visto mencionado este genial Memex cortazariano, sí se ha querido ver como texto pre-hipertextual Rayuela, catalogada por su estructura de múltiples rutas de

24 Vannevar BUSH, "As We May Think", Atlantic Monthly, julio 1945, asequible en: http://www.theatlantic.com/doc/194507/bush, fecha de consulta: 3 de octubre de 2010.

25 George P. LANDOW, Hypertext 2.0. The Convergente of Contemporary Critical Theory and Technology, Baltimore, Johns Hopkins UP, 1997, 3.

${ }^{26}$ Julio CORTÁZAR, "De otra máquina célibe", La vuelta al día en ochenta mundos, México, Siglo Veintiuno editores, 1969, 79-88. También recuperable en la red, asequible en:

http://www.literatura.org/Cortazar/Vuelta_al_dia/LV_maquina.html, fecha de consulta: 3 de octubre de 2010. 
lectura como novela infinita ${ }^{27}$ incluso sin hacer referencia a estas facetas tecnológicas. La definición propuesta por Landow, como otras muchas, tiene en su esencia la definición de hipertexto como nodo más enlace (node plus link). ${ }^{28}$ Así, en Rayuela -imaginemos la Rayuel-O-Matic instalada en nuestro salóntenemos los bloques o capítulos que actúan como nodos enlazados mediante la sugerencia numérica del capítulo correspondiente al final del bloque. El tablero inicial de Rayuela, explicitando este mecanismo, es un tablero de dirección, y nos remite por esencia al concepto de itinerario (path), itinerario que mediante los enlaces indicados realiza el lector, hilándolos uno tras otro, nodo tras nodo, en el orden propuesto, tirando del hilo del ovillo, y creando una red tejida (network), tal como los propios personajes que juegan en su historia a esos encuentros y desencuentros y necesitan elaborar sus propios itinerarios para poder cumplir y dar sentido a un juego que les impide comunicarse entre ellos. ${ }^{29}$

Sentados en el café reconstruían minuciosamente los itinerarios, los bruscos cambios, procurando explicarlos telepáticamente, fracasando siempre, y sin embargo se habían encontrado en pleno laberinto de calles, casi siempre acababan por encontrarse y se reían como locos, seguros de un poder que los enriquecía...

Así, los puentes, las calles, el subte de París, forman en la historia narrada líneas e hilos recorridos que esperan cruzarse unos con otros y producir así un encuentro, un conjunto de nudos-nodos vitales de seres que convergen enlazados en una comunicación por momentos antes de seguir su itinerario, su camino, la búsqueda. Recordemos ahora que un nudo es también donde se cruzan varias vías de comunicación. ${ }^{30}$ En su estructura, las dos y más posibles lecturas de la novela se cruzan entre sí numerosas veces, cuando al final de capítulo se sugiere la lectura del otro marcado o de seguir con el sucesivo, a modo de estaciones de metro que conectan con líneas diversas. Se crean en los nodos posibles bifurcaciones, a manera de las ramas de los árboles. Tenemos por tanto un mapa de la rayuela y una posible rayuela-mapa que podría convertirse en rayuela-laberinto (Borges y sus senderos mediante) y es en todos los casos el resultado una rayuela-red (web, net). Un gran ovillo de hilos sobre hilos lleno de nudos.

27 Scott SIMPKINS, “The Infinite Game: Cortazar's Hopscotch", The Journal of the Midwest Modern Language Association 23.1, 1990, 61-74.

28 Susana PAJARES TOSCA, Literatura digital: el paradigma hipertextual, Cáceres, U de Extremadura, 2004, 35.

${ }^{29}$ TEDESCO, op. cit., 148.

${ }^{30}$ DRAE, op. cit., voz nudo, 8. 
Así, es el hilo narrativo que ayuda a tejer el lector en madeja el que puede dar sentido último a la novela, surgiendo de un caos deshilachado que intenta explicarse y ordenarse a posteriori como búsqueda de un sentido, lo mismo que los personajes en su propia vida:

- ... ¿tu vida es una unidad para vos?

- No, no creo, son pedazos de cosas que me fueron pasando.

- Pero vos a tu vez pasabas por esas cosas como el hilo por esas piedras verdes. $^{31}$

El entramado nodal de esta rayuela-vida nos remite a la fabricación de esa alfombra-tapiz mencionada antes, cuyos hilos anudados conforman en su red las diferentes escenas por las que saltaba el niño Gregorovius. La rayuela-tapiz. Un tapiz de apariencia caótica que tiene su representación gráfica al final del episodio sobre la Rayuel-O-Matic: el itinerario de la segunda lectura propuesta de Rayuela se muestra impreso sobre un diagrama que representa el recorrido numérico trazado de capítulo a capítulo siguiendo la tabla de direcciones. Cortázar llama al resultado "proyección gráfica bastante parecida a un garabato", ${ }^{32}$ quizás porque está en dos dimensiones, pero lo que claramente muestra el dibujo es un gran ovillo de hilos sobre hilos lleno de nudos.

Quizás esto explica que el lector se sienta ante Rayuela y sus personajes un poco como la Laura de Divertimento descubriendo el interior translúcido de su ovillo anudado, en el que la "entera estructura se modifica por completo, ríos y mares filamentosos cambian de tamaño y lugar, se abren lampos y se espesan relieves, pero los nudos siempre ahí". ${ }^{33}$ La rayuela-mandala. Y el nudo como nodo, pues nodo, que procede también del latín nodus, es "cada uno de los puntos que permanecen fijos en un cuerpo vibrante. En una cuerda vibrante son siempre nodos los extremos, y puede haber varios nodos intermedios". ${ }^{34}$ Nuestra rayuela vibrante tiene la forma ya de un ovillo donde al agitarlo se modifica su estructura, pero los nudos siempre ahí.

\section{El ovillo nodal}

El capítulo 62 de Rayuela, muy cercano en su posición gráfica a un gran nudo enmarañado que puede advertirse en el diagrama representativo de la lectura de Rayuela mencionado antes, nos sirve a los lectores como un prólogo y una poética puentes, un enlace nodal al fin y al cabo, hacia 62, modelo para armar (1968). El

${ }^{31}$ CORTÁZAR, Rayuela, op. cit., 212-213.

${ }^{32}$ CORTÁZAR, La vuelta al día en ochenta mundos, op. cit., 88.

${ }^{33}$ CORTÁZAR, Divertimento, op. cit., 47.

${ }^{34}$ DRAE, op. cit., voz nodo, 2. 
capítulo 62 se adscribe a una de las reflexiones teóricas sobre la literatura del personaje profesor Morelli, y allí propone una idea de novela donde la psicología al uso no explicaría el comportamiento de sus personajes. Así,

la conciencia y las pasiones de los personajes no se ven comprometidas más que a posteriori. Como si los niveles subliminales fueran los que atan y desatan el ovillo del grupo comprometido en el drama. ${ }^{35}$

Un ovillo de personajes atados y desatados por lo subliminal que nos lanza a la novela, bien enmarañada, que es 62, modelo para armar: de nuevo encontraremos en su centro a uno de los habituales grupos de amigos al estilo Cortázar, pero en esta ocasión los encuentros entre ellos no sucederán en el piso de alguno de ellos, como en Divertimento, ni en las calles de París, como en Rayuela, sino en un Londres, París y Viena en sucesión y al mismo tiempo en una superposición de los tres, en un espacio común que es una abstracción realizada y posible, real, que ellos denominan la ciudad. Globo terrestre ovillo que ha crecido y se complica.

Ya Alazraki ha explicado cómo 62, modelo para armar constituye una novelacalidoscopio armada "como un tubo en el que tres planos espaciales -Londres, Viena y París- forman un prisma de espejos ${ }^{\$ 36}$ y cuyos capítulos se deben unos a otros en relación dependiente, "dependen el uno del otro, se reflejan el uno en el otro, muy a la manera de los espejos de un calidoscopio que funcionan desde su adyacencia y su naturaleza autorreflexiva" ${ }^{37}$ La narración hace girar esos espacios formando un conglomerado para el observador que es la ciudad superposición de prismas- y en ellos los sucesos de los personajes se ven igualmente superpuestos desdoblándose en una combinatoria de ecos del pasado y el futuro como las figuritas en un calidoscopio. ${ }^{38} \mathrm{El}$ lector es un tercer ojo que debe hilar las cuentas del collar, que aparecen como flotando en varios planos. ${ }^{39} \mathrm{Al}$ igual que flotan los varios planos superpuestos de un ovillo, hilo sobre hilo. Pero esta explicación perfecta no explicita la presencia posible de nudo alguno. Y sin embargo, el calidoscopio, como destaca el propio Alazraki, ${ }^{40}$ tiene como primera figurita esencial un comienzo narrativo que aglutina las claves de todo lo demás en la novela, inicio que por cierto es desencadenado por

\footnotetext{
${ }^{35}$ CORTÁZAR, Rayuela, op. cit., 523.

36 Jaime ALAZRAKI, "62, modelo para armar: novela calidoscopio", Revista Iberoamericana, 47, $1981,158$.

37 Ibidem, 158-9.

${ }^{38}$ Ibidem, 159-62.

${ }^{39}$ Ibidem, 162.

${ }^{40}$ Ibidem, 157.
} 
la acción de ese nivel subliminal exigido por Morelli para crear la novela. Busquemos ahí el nudo de este ovillo.

Lo subliminal comienza, por tanto, en el famoso inicio de la novela en el que Juan, que pasa una nochebuena no sabe muy bien por qué en el restaurante Polidor ante una botella de Sylvaner, lee una página al azar de un libro de Michel Butor que no supo muy bien por qué lo había comprado, e inmediatamente después escucha a un comensal gordo, al que ve por el espejo frente a él y al que escucha, claro, a sus espaldas, pedir en francés un "castillo sangriento".

En ese momento (estaba cerrando el libro porque no tenía ganas de leer y la luz era pésima) oyó distintamente el pedido del comensal gordo y todo se coaguló en el acto de alzar los ojos y descubrir en el espejo la imagen del comensal cuya voz le había llegado desde atrás. Imposible separar las partes, el sentimiento fragmentado del libro, la condesa, el restaurante Polidor, el castillo sangriento, quizá la botella de Sylvaner. ${ }^{41}$

Todo se precipita instantáneamente en él, "porque en ese vacío vertiginoso las metáforas saltaban hacia él como arañas". "Los elementos que provocan el instante total de revelación (el libro, la condesa, el restaurante Polidor...) llegan en forma de nodos mentales, como puntos que permanecen fijos en ese cuerpo vibrante que son los pensamientos de Juan y luego serán la novela, y son enlaces nodales (si recordamos el hipertexto) porque permiten unir y evocar-recorrer esas experiencias múltiples y superpuestas en la cabeza -ese Memex natural- de Juan, a las que luego remitirá la novela amplificándose. En este sentido, estos enlaces nodales lo son propiamente como hipertexto, si tomamos como ejemplo la definición que del uso (poético) de un enlace hipertextual da Pajares Tosca:

Los enlaces son herramientas semánticas que poseen un significado propio, pero también sugieren otro. Un desarrollo del sentido del texto que tenemos que imaginar antes de verlo. Los enlaces nos obligan a pensar asociativamente y a anticipar significados. ${ }^{43}$

Así, todo un ovillado microcosmos de proyecciones y relaciones fragmentarias convergen en ese mismo instante como un todo kairológico presente, pasado, futuro en un solo tiempo psicológico- de lo que va a ser el libro. Si vale la comparación, lo vivido por Juan psicológicamente es lo que la física actual, basada en la teoría de la relatividad einsteniana, explicaría como una serie de sucesos (puntos en el espacio-tiempo) que convergen entre sí por una

\footnotetext{
${ }^{41}$ Julio CORTÁZAR, 62, modelo para armar, Barcelona, Bruguera, 1982, 20.

42 Ibidem, 21.

${ }^{43}$ PAJARES TOSCA, op. cit., 101.
} 
densa atracción de gravedad y conforman una singularidad, que es "una región donde la curvatura del espacio-tiempo es tan grande que sus leyes ya no operan en el sistema, esto significa que es un punto casi cero donde se concentra una enorme cantidad de materia, siendo usualmente el centro de un agujero negro". ${ }^{44}$ Toda la materia de la novela se vuelca o colapsa de forma condensada en esas páginas iniciales, y como un big bang va a expandirse y armarse posteriormente como desarrollo de la novela. Esa singularidad inicial es entonces el origen o condensación de todo lo demás, como un ideograma psíquico en la mente de Juan: "Un hecho casual precipita las claves de una posible lectura de esa historia apenas aludida desde las piezas aisladas de un rompecabezas que la novela procederá a armar". ${ }^{45} \mathrm{Y}$ esa singularidad o colapso gravitacional de la narrativa que en la novela se nombra como coágulo, una forma colapso y nudo arterialcontiene y colapsa en sí el resto de la novela, pues recordemos que para Juan resulta "imposible separar las partes, el sentimiento fragmentado del libro, la condesa, el restaurante Polidor, el castillo sangriento, quizás la botella de Sylvaner" ${ }^{46}$ Esta totalidad, sin embargo, y por caótica que pueda parecer, vemos que sugiere en la reunión de sus elementos un enlace entre ellos, una asociación, proyectora de múltiples itinerarios posibles mostrados en fragmentos y escenas, que todavía el lector no puede comprender, ni trabar, ni tejer, pero que ve que están allí, conformando un gran ovillo anudado que atrae todas las definiciones anteriores del nudo: 62, modelo para armar es en su inicio un lazo que se estrecha y cierra, es trabazón de sucesos, punto de una red, unión y vínculo, problema, e incluso algo más: nos hallamos ante una singularidad-nudo de cuatro dimensiones, porque, como proponía Morelli, estamos en "un territorio donde la causalidad psicológica cedería desconcertada", y sin causalidad hemos anulado el tiempo y por tanto tiempo y espacio pueden superponerse y confundirse, o no importar. Como esta situación sólo puede darse en una singularidad, en lo más parecido a un agujero negro, la simultaneidad inicial de la novela mezclando tiempos, personas, lugares y nodos desencadenantes se hace posible, y por su naturaleza singular busca atraer, abarcar e implicar la totalidad

\footnotetext{
${ }^{44}$ WIKIPEDIA en español, asequible en: http://es.wikipedia.org/wiki/Portada, fecha de consulta: 21 de abril de 2009. Voz singularidad espacio-temporal. La singularidad "implica la ruptura de las leyes matemáticas que definen la geometría del espacio-tiempo que conocemos. Sería un punto en el cual la curvatura del espacio-tiempo se haría infinita y que está oculta al observador por el horizonte de sucesos". Diccionario Sirius de astronomía, Madrid, Sirius, 2001, 133.

45 ALAZRAKI, op. cit., 157.

46 CORTÁZAR, 62, modelo para armar, op. cit., 20. Recuérdese que una singularidad espaciotemporal constituye, además, un todo coagulado de materia, difícil de separar: una "densidad de materia infinita". Stephen W. HAWKING y otros, El futuro del espaciotiempo, Barcelona, Crítica, 2007, 202.
} 
de la novela, que sería así un enorme ovillo-agujero negro. ¿Totalidad, entonces, fragmentada? David Bohm, físico descubridor del holograma, ha apuntado que el universo está conectado en todos sus elementos -incluido el tiempo- y que esa red de conexiones aún no bien estudiada por la ciencia actual permitiría entender el caos como parte de un orden implicado, un orden que está ahí y que sólo necesita tiempo para desarrollarse y hacerse evidente. ${ }^{47} \mathrm{~A}$ modo de caos inicial se presenta el nudo de 62, modelo para armar, un ovillo-nudo cuatridimensional cuyos elementos nodales contienen las claves del desarrollo de los personajes y sucesos de la novela, a los que enlaza y proyecta en una zona, la ciudad, área donde el tiempo ha quedado anulado, y como en toda singularidad, "fallan las leyes actualmente conocidas de la física". ${ }^{48} 62$, modelo para armar representa esa suspensión mediante el sistema microcósmico elaborado en ella, y esa suspensión -planteada desde la psicología del individuo- afecta a la narrativa completa creando una obra perfectamente autocontenida cual universo con leyes propias. Obra en la que sugiero, para un estudio detallado, que sus partes, gracias a esa estructuración con sus múltiples enlaces nodales y asociaciones, a sus espejos calidoscópicos, son el reflejo unas de otras, como conteniéndose y expandiéndose al mismo tiempo: en definitiva, cada parte reflejando el todo, como un holograma.

Se dice que de un agujero negro es prácticamente imposible escapar, pues todo lo que cae tras su horizonte de sucesos es absorbido por él: así todos los elementos, sucesos, relaciones que entran en la novela, por dispares que parezcan, se asimilan inmediatamente mediante nuevas asociaciones a ese núcleo de asociaciones iniciales que lo atrae todo y todo lo genera, promoviendo el crecer de la novela en su masa oscura, complejísimo haz de enlaces superpuestos, nudos y nodos en formación dinámica, hilo mordiéndose, ovillo creciente complejo y calidoscópico, hologramático, al fin y al cabo, morelliano.

\footnotetext{
${ }^{47}$ David BOHM, La totalidad y el orden implicado, Barcelona, Kairos, 1987. Véase también, para una explicación desde la teoría del caos, el libro de Briggs: John BRIGGS y F. David Peat, Espejo y reflejo: del Caos al Orden. Guía ilustrada de la teoría del caos y la ciencia de la totalidad, Barcelona, Gedisa, 1994.

${ }^{48}$ Domingo Agustín VÁZQUEZ, Diccionario de ciencias, Madrid, Complutense, 2004, 27.
} 